and ventilated with $100 \%$ oxygen. External massage may be ineffective because of the grossly overdistended lungs, and in such cases internal cardiac massage can be a life-saving measure. ${ }^{7}$

Most patients with status asthmaticus will recover if they reach hospital alive provided efficient facilities for respiratory intensive care are available, but unfortunately many die at home or on their way to hospital. The reasons for this include inadequate routine medical supervision of asthmatic patients in general, failure by patients, relatives, and doctors to recognize crisis situations, inadequacies in the ambulance service and in the hospital admission system, overuse of bronchodilator aerosols, and inadequate dosage of corticosteroids. Much can be done to eliminate these failures of action and communication. Ideally, every patient with severe asthma should be the special responsibility of one particular medical or respiratory unit, which will guarantee immediate admission to hospital whenever the need arises. Only in this way can unnecessary deaths be avoided.

1 Palmer, K. N. V., and Diament, M. L., Lancet, 1967, 2, 1232.

2 Rees, H. A., Millar, J. S., and Donald, K. W., Quarterly fournal of Medicine, 1968, 37, 541.

s Sheehy, A. F., DiBenedetto, R., Lefrak, S., and Lyons, H. A., Archives of Internal Medicine, 1972, 130, 37.

- Grant, I. W. B., Lancet, 1966, 1, 363.

5 Choo-Kang, Y. F. J., Parker, S. S., and Grant, I. W. B., British Medical fournal, 1970, 4, 465 .

- Ambiavagar, M., and Jones, E. S., Anaesthesia, 1967, 22, 375.

' Grant, I. W. B., Kennedy, W. P. U., and Malone, D. N., British Medical Fournal, 1968, 2, 429.

\section{Hodgkin's Disease: A Clue or a Fluke?}

A striking series of cases of Hodgkin's disease has recently been described in some detail ${ }^{1}$ in a group of persons who attended or were connected with a certain high school in Albany, New York State. In a preliminary communication ${ }^{2}$ N. J. Vianna and his colleagues had reported that, after a colleague had drawn their attention to an unusual number of cases in this school, they found four members of the 1953-5 graduating classes to have died from the disease and a further eight cases among their friends, relatives, classmates, or contacts. Additional interlinked cases have now been discovered, and, in all, out of 42 cases of lymphoma studied, no fewer than 34 (of which 31 were Hodgkin's disease) could be linked directly or through a contact. The diagnosis in these cases had been made in the period 1948-70 in patients aged 14-74, and of these 15 were aged under 25 years. All the main histological subtypes were represented. Two smaller but separate groups of linked cases were found in other parts of New York State. The authors interpret these findings as suggesting that Hodgkin's disease is an infective condition with a carrier state and a long incubation period.

To what extent should these conclusions be regarded as established? Do the Albany findings merely represent a rare but nonetheless chance phenomenon, or do they indicate in unusually dramatic form a real tendency for Hodgkin's disease to be transmitted from person to person? This problem unfortunately is far from straightforward. Because determined attempts have seldom, if ever, been made to connect persons in this way, the number of links expected in so heterogeneous a group is difficult to imagine. The authors attempted to control their observations by finding how many of 18 patients with burns treated in hospital could be linked.
These patients had been matched for age, sex, race, and residence in Albany County with 18 of the first 21 cases of Hodgkin's disease. No links could be found between the patients even through an intermediary. Though the use of patients with burns as controls seems reasonable, the 18 patients for whom controls were chosen represent only a fraction of the 208 cases recorded in Albany County in the study period. Moreover, these 18 cases had largely been identified because of the existence of links, and indeed the group had initially attracted attention on this account.

Because coincidences do occur, to evaluate the possibility that Hodgkin's disease is transmitted by contact between patients or "carriers," evidence of such contact must be sought among patients with Hodgkin's disease and among suitably matched controls in areas where clustering has not been suspected. If in these circumstances appreciably more contact is found among cases than controls, then indeed this would constitute presumptive evidence of person-to-person transmission. Such studies have yet to be reported, though they have been initiated both in the U.S.A. ${ }^{1}$ and in Great Britain. ${ }^{3}$ Other supporting evidence for the infective hypothesis was not found. Thus there was no obvious consistency in latent periods or degree of interpersonal contact between linked cases, there being only one example of intrafamilial Hodgkin's disease (an uncle and niece). It is also relevant to note that the incidence of Hodgkin's disease had increased in Albany County during the period.

The evaluation of case-clusters of a disease not usually regarded as infectious is not a new problem. Leukaemia has attracted such attention because aggregations of cases, particularly in children, have been reported from time to time, though never on the scale of the Albany "outbreak." If cases are plotted on a map their number and proximity will obviously depend on the population distribution. Certain statistical tests assume a uniform population density within urban areas, though this may be far from true. E. G. Knox was the first to distinguish clearly between different types of clustering and to focus particular attention on space-time clustering. ${ }^{5} \mathrm{He}$ also suggested an ingenious statistical test for its detection which demands no control group and no information about the size and density of the populations concerned. Interviews with the patients are not necessary but simply the dates and places of onset. All possible pairs of cases are considered, and the number of pairs which are "close" in both space and time is used as a measure of clustering, closeness being defined before the data are examined. Similar tests have been suggested by other workers. ${ }^{6-8}$ The validity of this type of approach has been confirmed in certain known infectious diseases. ${ }^{7}$

Hodgkin's disease as it occurred in the Manchester conurbation has been analysed by Knox's method, but though weak clustering was found in 1963 and $1964^{\circ}$ there was no sign of this in a more detailed analysis in the period 1962-8.10 This application of Knox's method is open to the criticism that is not best suited for a disease in which a long and variable latent period is suspected. For this situation an extension of the test has been proposed ${ }^{11}$ in which periods of susceptibility and infectivity are postulated for each patient. The use of this test in the study of Hodgkin's disease has so far not been reported.

The time-space clustering which these tests aim to detect usually involves the address of the patient at diagnosis. If the disease was contracted some years before symptoms developed, then clearly this address may be irrelevant. Similarly, if for some reason schools (as apparently in Albany) or 
place of work were important, then clustering of place of residence would not necessarily be expected. It can be seen therefore that these methods are crude in comparison with the collection of information about contacts directly from patients and their controls. On the other hand this approach entails difficulties in deciding what constitutes contact and how this can be established. However, much the most important requirement in such studies is the inclusion of an adequate control group. The theory of case-control studies in this field has recently been discussed.12

The Albany cases and the speculation they have provoked are to be seen against the background of existing knowledge of Hodgkin's disease. Certainly connexions between affected patients are seldom noted in normal clinical practice, though familial ${ }^{13} 14$ and marital ${ }^{13} 15$ cases are on record. B. MacMahon, ${ }^{16}$ in an extensive review of the epidemiology of the disease, concluded that the evidence favoured an environmental cause. This includes an association with high socio-economic status, an uneven geographic distribution, and racial differences in incidence. He also put forward persuasive arguments that Hodgkin's disease may consist of at least two disease entities, respectively affecting mainly young adults and the elderly and he considered that an infective cause was more likely in the former. Any study or test of possible clustering should therefore also be applied separately to these postulated entities.

1 Vianna, N. J., et al., Annals of Internal Medicine, 1972, 77, 169.

2 Vianna, N. J., Greenwald, P., and Davies, J. N. P., Lancet, 1971, 1 1209.

3 Kinlen, L. J, Pike, M. C., Smith, P. G., Annual Meeting of the Society for Social Medicine, Oxford, September, 1972.

Knox, E. G.; Applied Statistcs, 1964, 13, 25.

5 Knox, G., British fournal of Preventive and Social Medicine, 1964, 18 17.

6 Ederer, F., Myers, M. H., and Mantel, N., Biometrics, 1964, 20, 626.

Barton, D. E., David, F. N., and Merrington, M., Annals of Human Genetics, 1965, 29, 97.

8 Mantel, N., Cancer Research, 1967, 27, 209.

9 Alderson, M. R., and Nayak, R., fournal of Chronic Diseases, 1972,

10 Alderson, M. R., and Nayak, R., British fournal of Preventive and Socin' Medicine, 1971, 25, 168 .

11 Pike, M. C., and Smith, P. G., Biometrics, 1968, 24, 541.

11 Pike, M. C., and Smith, P. G., Biometrics, 1968, 24, 541 . Interactions in the Aetiology of Cancer. Primosten, Jugoslavia, September 1972.

13 De Vore, J., and Doan, C. A., Annals of Internal Medicine, 1957, 47, 300 .

14 Razis, D. V., Diamond, H. D., and Craver, L. F., Annals of Internal Medicine, 1959, 51, 933.

15 Mazar, S. A., and Straus, B., Archives of Internal Medicine, 1951,

16 MacMahon, B., Cancer Research, 1966, 26, 1189.

\section{Oncological Centres}

Last week Sir Keith Joseph announced at a meeting of the British Association for Cancer Research that he had decided to approve in principle the formation of four pilot regional oncological centres. These centres are to be set up in the South Manchester, Leeds, South-West Metropolitan, and Wessex regions. Several regional boards had already been examining how a regional oncological centre could be set up in their particular area. The overall plan is the brain child of Sir David Smithers and the standing sub-committee on cancer of the Central Health Services Council.

Following President Nixon's political commitment to the conquest of cancer and its massive appropriation of funds for this purpose, the Prime Minister invited Lord Zuckerman to prepare a report on the state of cancer research in the U.K. In this report, Lord Zuckerman succinctly outlined the purpose of the projected oncological centres: "They (the
D.H.S.S.) propose the establishment of regional organization (oncological centres) within the National Health Service whereby the whole range of activities related to cancer, from prevention to terminal care, from basic research to health education of the public would be developed in a co-ordinated way. Opportunities would be created for close collaboration between clinicians and research workers, postgraduate training would be provided and a career structure for research workers in cancer developed."

What will these centres be able to achieve and how will they operate? Unfortunately, unlike Mr. Nixon, Sir Keith did not give any indication of the funds to be made available to allow these new centres to carry out their pathfinding mission in the long drawn out battle against cancer. They, as pilots, should try to find the way in which an improved national service for cancer can eventually be achieved.

We can only guess at what might be involved as the details have still to be worked out and approved by the D.H.S.S. At Manchester, a centre of paediatric oncology, developments in immunology and the establishment of a chair of oncology endowed by the Cancer Research Campaign are a few of the highlights of their proposal. The large concentration of cancer therapy and research facilities at the Christie Hospital and the Paterson Laboratories can readily support a co-ordinated expansion. The South-West Metropolitan development will be centred at Sutton and be yet another phase in the steady build-up of cancer research and cancer therapy that has been undertaken by the Institute of Cancer Research and the Royal Marsden Hospital. Now they hope to co-operate with St. George's Hospital as well as the large district hospitals in the neighbourhood to provide a variety of clinical units for the treatment and study of malignant disease.

In the Leeds and Wessex regions the situation differs from the centres with large on-site cancer research institutes. In the Leeds regional centre it is suggested that this should be operationally based on its regional radiotherapy hospital. A key point in their plan is to bring forward the building programme for the expansion of this hospital, so it can more adequately fulfil its vital role in the centre's activities. It is expected the special units already formed for cancer therapy will be expanded and new units created where they can strategically do the best work. Bladder cancer, colon cancer, leukaemia, and gynaecological cancers are examples within the Leeds region where co-ordinated effort is already beginning to yield useful results. Wessex have indicated their interest lies especially in the lymphomas, breast cancer, and epidemiological studies.

It is increasingly evident that the concentration of patients with certain forms of malignant disease into special therapy units gives them the greatest chance of cure and the longest survival. In leukaemia, lymphoma, and choriocarcinoma the evidence that this is true has been proved beyond doubt, but always provided the disease is recognized early and the patient is sent to the special unit without delay.

Now is the time to find out whether special units are appropriate to the treatment of more forms of malignant disease, where all the staff for the investigation, management, and study of a particular form of cancer work as a team. The advantages seem to outweigh the view that medicine is becoming too specialized. The cancer centre organization should enable surgeons, physicians, radiotherapists, and research workers who want to work together to do so more easily and provide a liaison which should encourage the application of developments in basic research to the treatment of the 